BRE 116015

\title{
Effects of 2-Deoxy-D-Glucose on In Vitro Cat Carotid Body
}

\author{
A. OBESO, L. ALMARAZ and C. GONZALEZ
}

Departamento de Fisiologia y Bioquimica, Facultad de Medicina, Universidad de Valladolid, 47005 Valladolid (Spain)

(Accepted August 20th, 1985)

\begin{abstract}
Key words: carotid body — arterial chemoreceptor - 2-deoxy-D-glucose — adenosine triphosphate content -.. dopamine release - chemoafferent activity - metabolic hypothesis
\end{abstract}

\begin{abstract}
The process of chemosensory transduction in the arterial chemoreceptors is not well understood. According to the metabolic hypothesis of chemoreception, a decrease in arterial $\mathrm{pO}_{2}$ will produce a decrease in the adenosine triphosphate (ATP) content in the chemosensory type I cells, leading to release of a neurotransmitter and increased sensory neural activity. There is a paucity of direct experimental support for this hypothesis, and in the present work, we have tested the postulates of the metabolic hypothesis in an in vitro preparation of cat carotid body using 2-deoxy-D-glucose as an ATP-depleting agent. This preparation, when superfused with Tyrode containing $5 \mathrm{mM} \mathrm{Na}^{+}$-pyruvate instead of glucose, responds normally to hypoxia, low $\mathrm{pH}$ and acetylcholine, and maintains normal ATP levels. Under these conditions, 2-deoxy-D-glucose is a chemostimulant, i.e. electrical activity in the carotid sinus nerve is increased, with a threshold concentration of $0.25 \mathrm{mM}$ and a maximum response at about $2-4 \mathrm{mM}$. These concentrations of 2-deoxyglucose evoke a dose-dependent release of $\left[{ }^{3} \mathrm{H}\right]$ dopamine (synthesized from $\left[{ }^{3} \mathrm{H}\right]$ tyrosine) from the carotid bodies which parallels the electrical activity. The 2-deoxy-D-glucose-evoked release and electrical activity is dependent on the presence of extracellular $\mathrm{Ca}^{2+}$ These same concentrations of 2-deoxy-D-glucose significantly reduce the ATP content of the carotid bodies. The events postulated by the metabolic hypothesis, i.e. decrease in ATP content, release of a putative neurotransmitter and activation of the sensory nerve endings are found to occur simultaneously. A possible cause-effect relationship between these three events is discussed.
\end{abstract}

\section{INTRODUCTION}

The arterial chemoreceptors are excited by decreases in $\mathrm{p}_{\mathrm{a}} \mathrm{O}_{2}$ and $\mathrm{pH}$ and by increases in $\mathrm{p}_{\mathrm{a}} \mathrm{CO}_{2}$ and contribute to the respiratory adjustments seen in all physiological and pathological situations in which there are deviations from normality in blood gas tensions and $\mathrm{pH}$. The mechanisms by which these receptors detect the changes in those blood parameters are unknown. According to one hypothesis, known as the metabolic hypothesis ${ }^{4,15,38.39 .55}$ (see ref. 7 for a review), the overall transduction process in these receptors for the hypoxic stimuli will correspond to this sequence: hypoxia will decrease adenosine triphosphate (ATP) levels in the type I cells, which in turn will release a neurotransmitter capable of exciting the sensory nerve endings. This hypothesis is based on the assumption that because the metabolic poisons (inhibitors of the respiratory chain, uncouplers of oxidative phosphorylation and mitochondrial ATPase inhibitors) are potent chemostimulants they will decrease the ATP content in the chemoreceptors, as they do in other tissues. The metabolic hypothesis does not consider the mechanisms involved in the detection of the other two physiological stimuli $\left(\mathrm{p}_{\mathrm{a}} \mathrm{CO}_{2}\right.$. $\mathrm{pH}$ ).

In the present study, we have tested the postulates of the metabolic hypothesis by using 2-deoxy-D-glucose $(2-D G)$ in an in vitro preparation of the cat carotid body (CB). 2-DG is an analogue of glucose which enters the cells by the same carrier as glucose. In the presence of ATP, it is phosphorylated by hexokinase to 2-deoxy-glucose-6-phosphate (2-DG-6P) and it is not further metabolized ${ }^{51,52}$. We have chosen 2-DG to test the metabolic hypothesis because in our experimental conditions (preparations maintained in pyruvate-Tyrode free of glucose), it is an effective ATP-depleting agent, it is free of known side-actions

Correspondence: C. Gonzalez, Departamento de Fisiologia y Bioquimica. Facultad de Medicina. Universidad de Valladolid. 47005 Valladolid, Spain. 
and its mechanism for depleting ATP (increased ATP expenditure) is different from that of the mitochondrial poisons which deplete ATP by blocking synthesis. Therefore, if 2-DG is a chemostimulant, this should allow a broader formulation of the metabolic hypothesis in the sense that a reduction in ATP levels, whatever the mechanism, is accompanied by an increase in chemoreceptor activity. We found that CBs superfused with balanced saline containing pyruvate as a nutrient instead of glucose, responded normally to different stimuli (low $\mathrm{O}_{2}$, low $\mathrm{pH}$ and acetylcholine $(\mathrm{ACh})$ ). We found also that the presence of $2-\mathrm{DG}$ in the superfusion media (Tyrode-pyruvate) catused a dose-dependent increase in the electrical activity of the carotid sinus nerve (CSN) and in the release of $\left[{ }^{3} \mathrm{H}\right]$ dopamine $\left(\left[{ }^{3} \mathrm{H}\right] \mathrm{DA}\right)$ from the type 1 cells. This $2-$ DG-induced release was dependent on the presence of extracellular $\mathrm{Ca}^{2+}$. Finally, we found direct relationships amongst the chemoresponses, the amount of 2-DG phosphorylated and the decrease in the ATP content in the $\mathrm{CB}$. Taken together, these findings give experimental support to the metabolic hypothesis. Some of the results have been published in abstract form ${ }^{42}$.

\section{MATERIALS AND METHODS}

\section{Surgery}

Adult cats $(2-3.5 \mathrm{~kg})$ were anesthetized with sodium pentobarbital (30-40 mg/kg, i.p.), tracheostomized and placed on a respirator. Subsequent surgery varied slightly in the different types of experiments: (1) When the electrical activity in the CSN was to be recorded, a double ligature was placed on the external carotid artery. A section between the ligatures allowed better identification of the CSN which was dissected out and removed together with the carotid bifurcation. The block of tissue was placed in a lucite chamber filled with ice-cold $100 \%$ $\mathrm{O}_{2}$-equilibrated Tyrode containing (in $\mathrm{mM}$ ): $\mathrm{NaCl}$. 140; $\mathrm{KCl}, 4.7 ; \mathrm{CaCl}_{2}, 2.2 ; \mathrm{MgCl}_{2}, 1.1$; HEPES, 10 ; glucose, 5.5; adjusted to $\mathrm{pH} 7.4$ with $1 \mathrm{~N} \mathrm{NaOH}$. (2) In the experiments in which the measurement of electrical activity was not required (experiments to measure ATP levels), a clamp was placed cephalad to the carotid sinus and another on the common carotid artery, and within $40 \mathrm{~s}(25-40 \mathrm{~s})$ the bifurcation was placed in the lucite chamber as before. In both cases, the operative field was kept mont whth warn? saline.

\section{Electrophysiological recording and release of $1 \mathrm{H} / \mathrm{do}$} pamine

Under a dissecting scope (Leitz), the ( $B$, with the CSN attached were prepared for recording as previously described ${ }^{19}$. In the experiments in which the release of $\left[{ }^{3} \mathrm{H}\right]$ dopamine $\left(\left[{ }^{3} \mathrm{H} \mid \mathrm{DA}\right)\right.$ was to be meas. ured, the preparations were incubated for $3 \mathrm{~h}$ in 500 $\mu \mathrm{l}$ of $100 \% \mathrm{O}_{2}$-equilibrated Tyrode containing the catecholamine precursor $\left[{ }^{3} \mathrm{H}\right]$-tyrosine $\left(2,6-\left[{ }^{3} \mathrm{H}\right]\right.$ tyrosine; $20 \mathrm{Ci} / \mathrm{mmol}$, Amersham) at a concentration of $20 \mu \mathrm{M}$ and containing also $100 \mu \mathrm{M}$ of the tyrosine hydroxylase cofactor, 6-methyl-tetrahydropterine (Sigma) and $1 \mathrm{mM}$ ascorbic acid. Under these incubating conditions, the $\mathrm{CB}$ synthetized about 20 pmol of [ $\left.{ }^{3} \mathrm{H}\right] \mathrm{DA}\left(\simeq 4 \times 10^{5} \mathrm{cpm}\right)$ (unpublished). Whether or not the release of $\left[{ }^{3} \mathrm{H}\right] \mathrm{DA}$ was monitored, the CBs were mounted in a drop superfusion chamber which allowed continuous flow-rate superfusion $(0.4$ $\mathrm{ml} / \mathrm{min}$ ) with different solutions at $37^{\circ} \mathrm{C}$. recording of electrical activity in the whole CSN with a suction electrode and collection of the superfusates for later analysis when needed ${ }^{19}$. The superfusates were collected in vials containing a carrier mixture (glacial acetic acid-20 mM ascorbic acid- $100 \mu \mathrm{M}$ cold DA) in the appropriate volume to yield a final $\mathrm{pH}$ in the superfusates of 3.2-3.6. The collection of the superfusates was made according to the following sequence: 5 min prior to the application of the stimulus (control), 5 min during the stimulus application and 4 more fractions of 5 and 10 min post-stimulus, totaling 45 min (duration of a single stimulus cycle; see Fig. 8). Normally, each experiment consisted of $4-6$ stimulus cycles. The superfusates were analyzed for ${ }^{3} \mathrm{H}$ labelled catecholamines released by adsorption on acid-washed alumina at $\mathrm{pH} 8.6$ and elution with $1 \mathrm{~N}$ $\mathrm{HCl}$ to recover all ${ }^{3} \mathrm{H}$-labelled catechol compounds ${ }^{5 x}$. Positive identification of the eluted ${ }^{3} \mathrm{H}$-labelled compounds was achieved by thin-layer chromatography (TLC) analysis according to Fleming and Clark ${ }^{21}$. Since the sum of $\left[{ }^{3} \mathrm{H}\right] \mathrm{DA}$ and $\left[{ }^{3} \mathrm{H}\right]$ dihydroxyphenylacetic acid $\left(\left[{ }^{3} \mathrm{H}\right]\right.$ DOPAC) accounted for $80-85 \%$ of the radioactivity present in the eluates (the rest being mostly $\left[{ }^{3} \mathrm{H}\right]$ tyrosine), we refer to the released material present in the eluates as [ $\left.{ }^{3} \mathrm{H}\right] \mathrm{DA}$. The stimulus-induced release was evaluated as follows: the mean re- 
lease during two control periods of two consecutive cycles was taken as basal release $/ 5$ min during that cycle, and the sum of any release exceeding this basal release in all cycle fractions was considered stimulusinduced release.

The action potentials from the CSN were led through an AC-coupled preamplifier and displayed on an oscilloscope. The amplified signals were also led through a window discriminator to a digital counter-printer which read the total number of action potentials during fixed periods of time $(1$ or $10 \mathrm{~s})$. The stimulus-induced electrical activity was evaluated similarly to the release of [ $\left.{ }^{3} \mathrm{H}\right] \mathrm{DA}$; the maximum activity elicited by a stimulus $(\mathrm{Hz})$ was divided by the mean basal activity in the 5 min prior to the application of the stimulus $(\mathrm{Hz})$, thus giving induced activity relative to control.

\section{ATP measurements}

Taking into consideration the lability of ATP levels ${ }^{35}$, special precautions were taken: (1) As mentioned before, the carotid bifurcation was removed within $40 \mathrm{~s}$ after clamping the common carotid artery. (2) The Tyrode in the lucite chamber was kept at $0-2{ }^{\circ} \mathrm{C}$ and renewed every $2 \mathrm{~min}$ to avoid warming and significant drops in $\mathrm{O}_{2}$ tension. (3) The dissection and thorough cleaning of the $\mathrm{CB}$ was completed within 4-6 min, but in all instances the CBs remained in the chamber for $6 \mathrm{~min}$. ATP levels in both CBs of the same animal measured at this stage showed great variability, probably due to different degrees of manipulation. (4) Incubation of the CBs in $100 \% \mathrm{O}_{2}$ equilibrated Tyrode at $37{ }^{\circ} \mathrm{C}$ for $15-60$ min resulted in higher ATP levels and a drastic reduction in the variability of the values obtained for both $C B s$ of the same animal, and therefore, the $\mathrm{CBs}$ were systematically preincubated for $25 \mathrm{~min}$ at $37^{\circ} \mathrm{C}$. (5) The effect of any given stimulus on the ATP levels was assessed on one $\mathrm{CB}$ from one animal, the contralateral $\mathrm{CB}$ serving as control. Both $\mathrm{CBs}$ were preincubated for $25 \mathrm{~min}$; the control $\mathrm{CB}$ was incubated for 5 additional min in the control solution and the test $\mathrm{CB}$ was similarly incubated for $5 \mathrm{~min}$ in the stimulus-containing medium. (6) The CBs were placed on pre-cooled $\left(-20{ }^{\circ} \mathrm{C}\right)$ homogenizer pestles and homogenized (glass to glass) in ice-cold $0.6 \mathrm{~N}$ PCA $(200 \mu \mathrm{l})$. The samples were centrifuged at $4{ }^{\circ} \mathrm{C}$ and the supernatants neutralized in the cold with $2.4 \mathrm{~N}$ potassium bi-

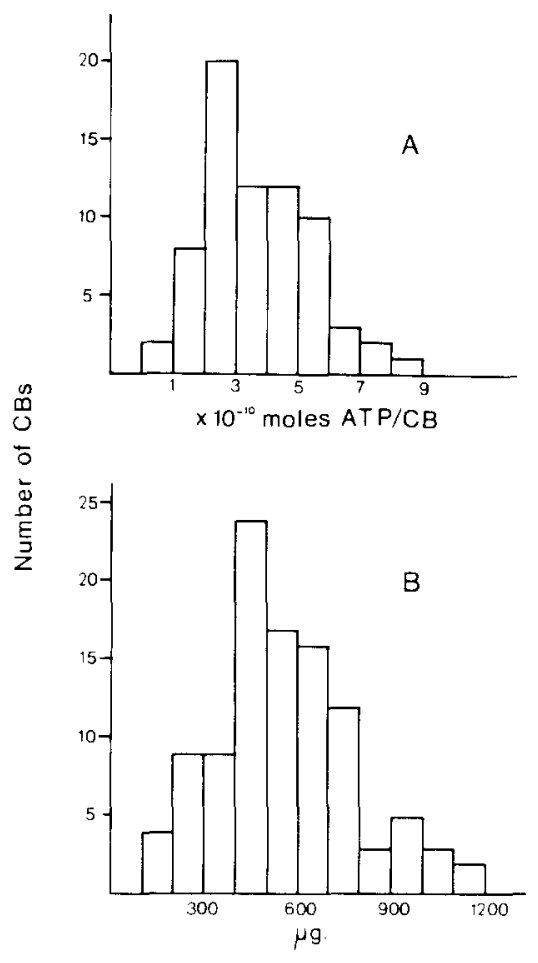

Fig. 1. A: distribution of the ATP levels found in the cat CB. ATP was assayed either radioenzymatically or by a photoluminescence-based assay; both methods gave the same levels. $\mathbf{n}=$ $70 ; \overline{\mathrm{X}}=3.7 \times 10^{-11} \mathrm{~mol} \mathrm{ATP} / \mathrm{CB} ; \mathrm{S}^{2} \mathrm{ATP}=2.95$. B : distribution of $\mathrm{CB}$ weights in the cat. Shown for comparative purposes is the distribution of $\mathrm{CB}$ weights from a previous study ${ }^{25} . \mathrm{n}=$ $104 ; \bar{X}=559.0 \mu \mathrm{g} / \mathrm{CB} ; \mathrm{S}^{2}=47,961$. The variances of both distributions are not statistically different $(P<0.01)$.

carbonate, and after 20 min centrifuged again. ATP was measured in the latest supernatants either radioenzymatically ${ }^{26}$ or by a photoluminescence-based method 28 . The sensitivities of both methods were better than $3 \times 10^{-12} \mathrm{~mol} /$ assay and yielded the same ATP values for the CB. Fig. 1A shows the distribution of ATP levels measured in 70 control CBs and the weight distribution of $104 \mathrm{CBs}$ observed in a previous work ${ }^{25}$. The variances of both distributions are not statistically different $(P<0.01)$.

\section{RESULTS}

\section{Superfusion conditions}

In preliminary experiments, it was found that in preparations superfused with $100 \% \mathrm{O}_{2}$-equilibrated Tyrode containing $5 \mathrm{mM}$ glucose, only with high 
2-DG concentrations $(>4 \mathrm{mM})$ in the superfusion media it was possible to obtain an increase in the CSN activity, and even this increase had a very slow onset. Superfusion with $100 \% \mathrm{O}_{2}$-equilibrated glucose-free Tyrode, on the other hand, produced a much larger and faster excitation of the $\mathrm{CB}$ chemoreceptors at 2-DG concentrations well below $1 \mathrm{mM}$. The use of glucose-containing Tyrode posed problems because in order to get the maximum ( $>80 \%$ ) excitatory effect, it was calculated on the basis of competitive inhibition kinetics that 2-DG should be raised to $20 \mathrm{mM}$. Since the CB chemoreceptors are very sensitive to osmotic changes ${ }^{23}$, the findings could be misleading. On the other hand, superfusion of the $\mathrm{CB}$
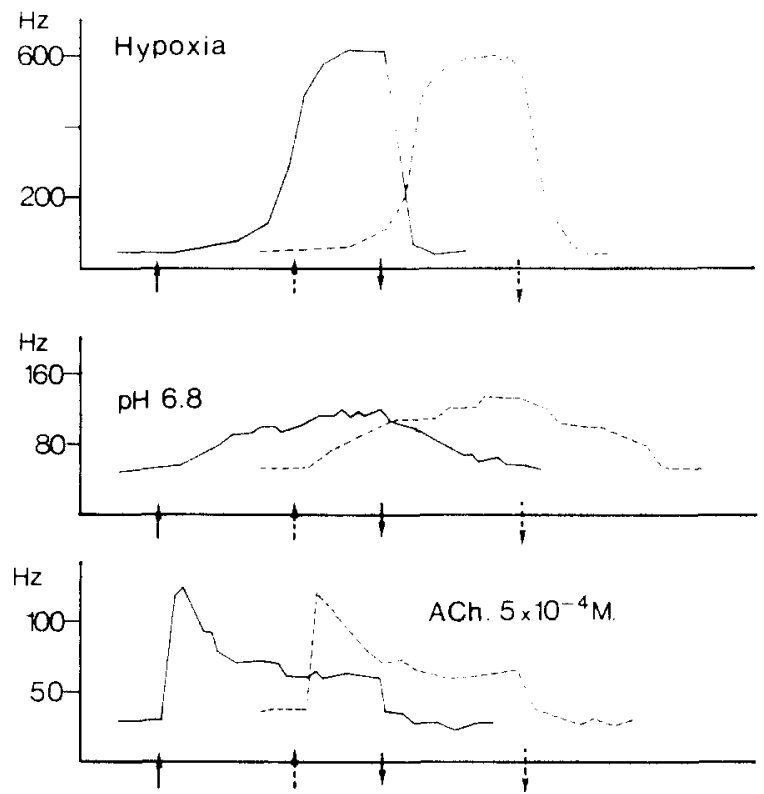

Fig. 2. Electrical activity of the CSN of one preparation superfused with Tyrode-glucose (continuous tracings) and Tyrodepyruvate (discontinuous tracings). The experiment started with perfusion of the $\mathrm{CB}$ with $100 \% \mathrm{O}_{2}$-Tyrode-glucose, and every 45 min the $\mathrm{CB}$ was stimulated first with low $\mathrm{O}_{2}\left(20 \% \mathrm{O}_{2}\right.$ balanced $\mathrm{N}_{2}$ )-containing solution, then with a $100 \% \mathrm{O}_{2}$-Tyrode-glucose at $\mathrm{pH} 6.8$ and finally with a $100 \% \mathrm{O}$-Tyrode-glucose containing $5 \times 10^{-4} \mathrm{M} \mathrm{ACh}$. Thereafter, the superfusion was made with $100 \% \mathrm{O}_{2}$-Tyrode-pyruvate. After allowing $1 \mathrm{~h}$ to wash out the glucose, the same pattern of stimulation was followed. In different experiments, the order of perfusion was alternated, but in all instances the stimuli lasted $5 \mathrm{~min}$ (between arrows). It must be stated that the CB chemoreceptors start to increase their electrical activity when the perfusion solution is equilibrated with $60 \% \mathrm{O}_{2}$ in $\mathrm{N}_{2}$ at the superfusion rate used in the present experiments. Under these conditions, a $20 \% \mathrm{O}_{2}-$ equilibrated solution represents a hypoxic stimulus of moderate to high intensity ${ }^{19}$. with glucose-free Tyrode was excluded as an experimental preparation because after about $1 \mathrm{~h}$ (range. 20 to $80 \mathrm{~min}$ ) in glucose-free media, there was a spontaneous increase in the CSN activity followed by unresponsiveness of the preparation to hypoxia ${ }^{3}$.

As an alternative energetic substrate to glucose, pyruvate $(5 \mathrm{mM})$ was tested. With pyruvate as substrate, the response to hypoxia, low $\mathrm{pH}$ and $\mathrm{ACh}$ was indistinguishable from that obtained with glucose as substrate (Fig. 2). Table I shows mean values of the electrical behavior of the $\mathrm{CB}$ when perfused with either glucose or pyruvate. Neither the basal activity nor the stimuli-induced responses were different from those obtained with glucose when the substrate was pyruvate. In addition, it was also found that the ATP levels measured after 30 min of incubation with glucose or pyruvate were not statistically different (Fig. 3). These findings, coupled to the fact that under Tyrode-pyruvate 2-DG was a powerful chemostimulant (see below), prompted us to use as perfusion media Tyrode-pyruvate equilibrated with $100 \%$ $\mathrm{O}_{2}$.

\section{Effects of 2-DG on the chemoreceptor activity}

In Fig. 4 an experiment is presented showing the characteristics of the electrical activity obtained on

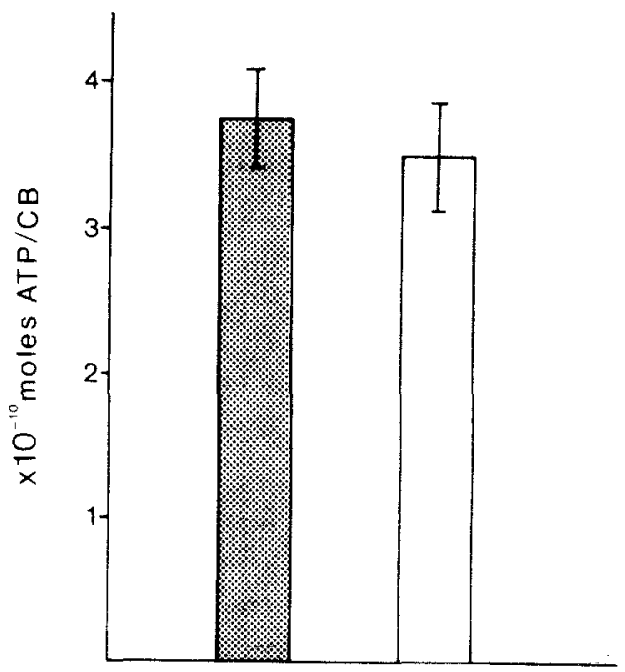

Fig. 3. ATP levels in cat CBs incubated for $30 \mathrm{~min}$ in Tyrodepyruvate (striped bar) or in Tyrode-glucose (clear bar). Pyruvate: $\mathrm{n}=14 ; \overline{\mathrm{X}}=3.76 ;$ S.E.M. $=0.37$. Glucose: $\mathrm{n}=19$ : $\bar{X}=3.48$; S.E.M. $=0.37$. All CBs of this figure were assayed by the luciferin-luciferase method. Comparisons: $t$-test, $P>$ 0.05 . 
TABLE I

Characteristics of the $C B$ response to different stimuli during superfusion with glucose $(G)$ and with pyruvate $(P)$

In all cases, the window discriminator was adjusted at the onset of the experiments to provide a basal activity (superfusion with $100 \%$ $\mathrm{O}_{2}$-equilibrated solution) in the range of 25-50 action potentials. The counting windows remained unchanged for the rest of the experiment. Data represent means \pm S.E.M. No statistical differences ( $t$-test) were observed in any of the parameters evaluated.

\begin{tabular}{|c|c|c|c|c|c|c|}
\hline & \multicolumn{2}{|l|}{ Hypoxia } & \multicolumn{2}{|l|}{$p H 6.8$} & \multicolumn{2}{|c|}{$A C h\left(5 \times 10^{-4}\right)$} \\
\hline & $G(n=9)$ & $P(n=7)$ & $G(n=16)$ & $P(n=14)$ & $G(n=11)$ & $P(n=9)$ \\
\hline Basal activity (BA) $(\mathrm{Hz})$ & $40 \pm 5$ & $48 \pm 6$ & $38 \pm 5$ & $35 \pm 5$ & $39 \pm 6$ & $38 \pm 4$ \\
\hline Peak activity (PA) $(\mathrm{Hz})$ & $296 \pm 66$ & $365 \pm 54$ & $98 \pm 13$ & $108 \pm 16$ & $109 \pm 16$ & $117 \pm 19$ \\
\hline Average activity (AA) $(\mathrm{Hz})$ & $171 \pm 30$ & $235 \pm 34$ & $71 \pm 10$ & $80 \pm 12$ & $83 \pm 13$ & $85 \pm 14$ \\
\hline Time-to-peak (s) & $253 \pm 20$ & $233 \pm 35$ & $210 \pm 17$ & $235 \pm 13$ & $77 \pm 16$ & $56 \pm 13$ \\
\hline $\mathrm{PA} / \mathrm{BA}$ & 7.4 & 7.6 & 2.6 & 3.1 & 2.8 & 3.1 \\
\hline AA/BA & 4.3 & 4.9 & 1.9 & 2.3 & 2.1 & 2.2 \\
\hline
\end{tabular}

superfusing the CBs for 5 min with different concentrations of 2-DG. Note (Fig. 4 inset) the dose-dependent response. Note also that the onset and the time to peak of the response decreased with increasing concentrations of 2-DG. And finally it can be seen that the recovery time (time for the electrical activity to return to the pre-stimulus levels) increased with increasing 2-DG (Fig. 4).

Fig. 5 shows dose-response curves for the effect of 2-DG on the electrical activity of the CSN. The upper curve was obtained from $10 \mathrm{CBs}$ which immediately upon dissection were mounted in the superfusion-recording chamber. The lower curve was obtained from $8 \mathrm{CBs}$ which had been incubated in Tyrode-

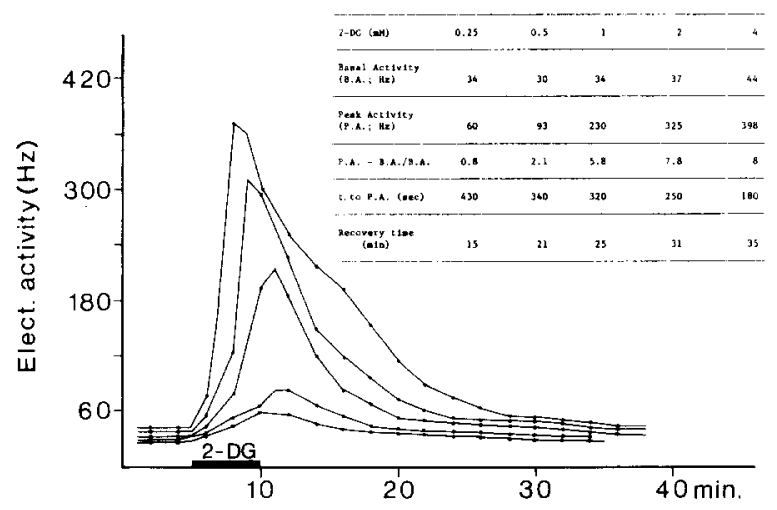

Fig. 4. Electrical activity elicited in the carotid sinus nerve by different concentrations of 2-deoxyglucose in the superfusing medium (Tyrode-pyruvate equilibrated with $100 \% \mathrm{O}_{2}$ ). Inset: characteristics of the electrical response. BA, basal activity; PA, peak activity; t to PA, time-to-peak activity (s); recovery time, time for the electrical activity to return to the basal activity (min) (single experiment). glucose for the $3 \mathrm{~h}$ period prior to electrophysiological recording (Fig. 5). Since this difference in the response upon incubation is not observed with other stimuli (hypoxia, low $\mathrm{pH}, \mathrm{CN}^{-}$), it appeared that it must have been related to some specific factor concerned with the mechanism of action of 2-DG. In this regard it must be mentioned that in two structures (the superior cervical ganglion and the adrenal medulla) embryologically similar to the type I cells ${ }^{30,33}$, there is an increase in the stores of glycogen upon incubation of the structures in vitro with $5 \mathrm{mM}$ glu-

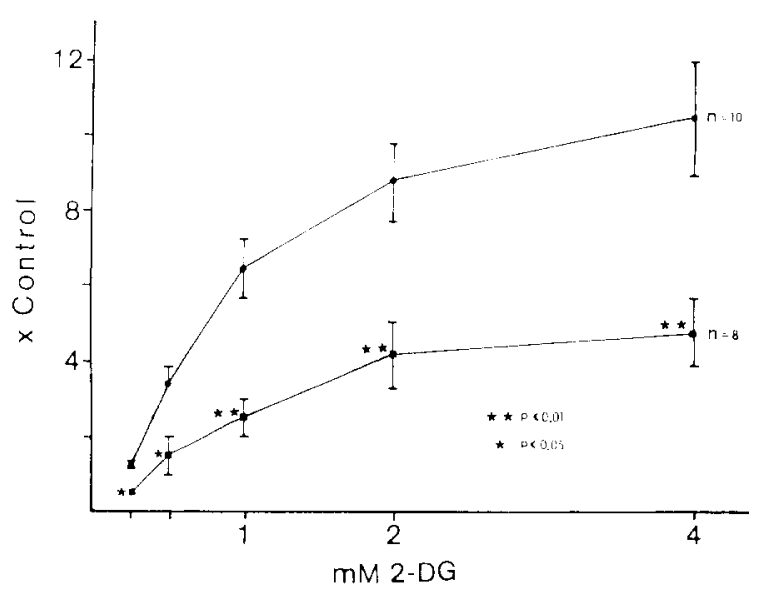

Fig. 5. Dose-response curves for 2-deoxyglucose on the electrical activity of the carotid sinus nerve expressed in relation to the control (times control activity). In all instances, the CBs were mounted in the recording chamber and superfused for $1 \mathrm{~h}$ with $100 \% \mathrm{O}_{2}$-equilibrated Tyrode-pyruvate before the initiation of the stimulation with 2-deoxyglucose. (O) Obtained from 10 carotid bodies ( $\overline{\mathrm{X}} \pm$ S.E.M.) immediately upon removal from the animals. (D) Obtained from 8 carotid bodies preincubated for $3 \mathrm{~h}$ in Tyrode-glucose. Comparisons: $t$-test, ${ }^{* *} P<$ $0.01 ;{ }^{*} P<0.05$. 
$\operatorname{cose}^{12.13,37}$. It may be that the breakdown of the glycogen during the recording period generates glucose. which competes with $2-\mathrm{DG}$ at the phosphorylation step (see Discussion; see also Fig. 9)

Effects of 2-DG on the release of $I^{3} H / D A$ from the type I cells: correlation with the electrical activity and ATPlevels

It is well-documented that the exocytotic release of neurotransmitters and hormones is a process which requires $\mathrm{ATP}^{49}$. It is also well-documented that in a great variety of secretory structures (brain tissue. adrenal gland, sympathetic endings, platelets), a decrease in ATP levels reduces rather than increases
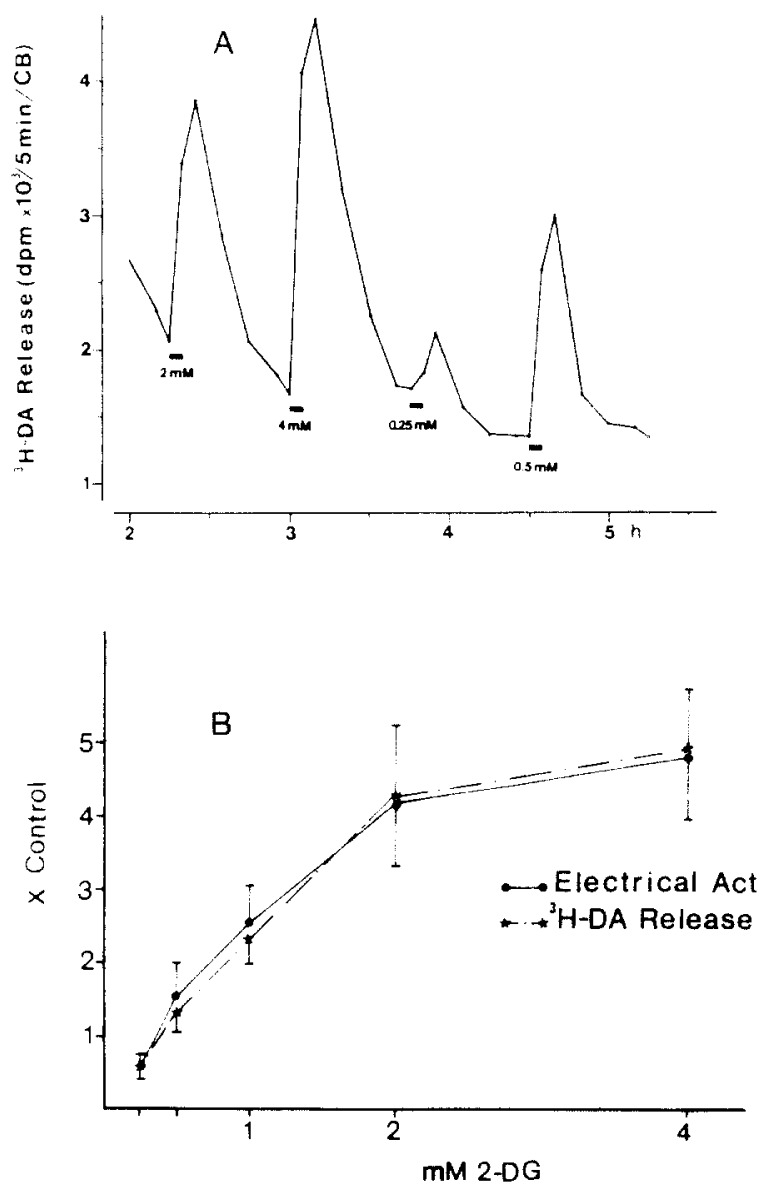

Fig. 6. A: effect of different concentrations of 2-deoxyglucose applied for $5 \mathrm{~min}$ (horizontal bars) on the release of $\left[{ }^{3} \mathrm{H}\right] \mathrm{DA}$ from the carotid body (single experiment). B: dose-response curves for 2-deoxyglucose on the electrical activity ( ) and [ $\left.{ }^{3} \mathrm{H}\right] \mathrm{DA}$ release $(\star \ldots-\star)^{\prime}$ ) obtained simultaneously in the same preparations. Points represent means \pm S.E.M. of 8 experiments. the secretory process $16,27,29,4,45,5$. Since the above facts are opposite to what the metabolic bypothesis predicts for the chemoreceptors, it was of gleat interest to establish first if $2-\mathrm{DG}$ induced the release of $\left[{ }^{3} \mathrm{H}\right] \mathrm{DA}$ from type 1 cells. and second it $2-\mathrm{DC}$ reduced the ATP levels in the C B.

Fig. 6A shows a single experiment in which it is evident that 2-DG applied for $5 \mathrm{~min}$ induced at release of $\left[{ }^{3} \mathrm{H}\right] \mathrm{DA}$ from a preloaded $\mathrm{CB}$ which was dependent on the concentration of the glucose analogue. Fig. $6 \mathrm{~B}$ shows the dose-response curves for both the release of $\left[{ }^{3} \mathrm{H}\right] \mathrm{DA}$ and the electrical activity obtained from 8 experiments.

Fig. 7 shows the effects of 2-DG $(1,2$ and $4 \mathrm{mM})$ on the ATP levels in CBs, compared to contralateral organs similarly incubated in the absence of 2-DG. Fig. 7 also shows the relative rates of $2-\left[{ }^{3} \mathrm{H}\right] \mathrm{DG}$ phosphorylation in the range of concentrations from 0.25 to $4 \mathrm{mM}$. The data presented in these last two figures (Figs. 6 and 7) certainly suggest that in the CB chemoreceptors there is a close relationship between the decrease in the ATP levels, the release of a putative neurotransmitter and the genesis of activity in the CSN, as the metabolic hypothesis proposes

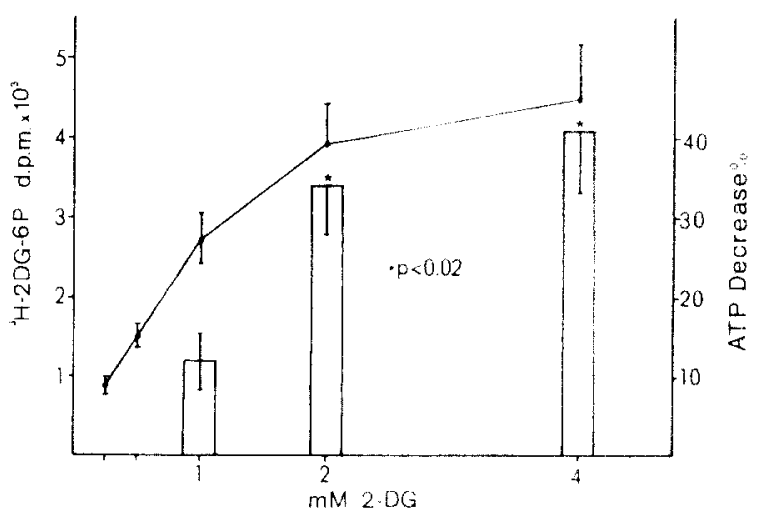

Fig. 7. Phosphorylation rates of $2-[3 \mathrm{H}]$ deoxy-D-glucose at ditferent concentrations. The curve was obtained by adding tracer amounts of the labelled glucose analogue to the vials containing the specified (abscissa) concentrations of the unlabelled analogue; the incubation time was $5 \mathrm{~min} .2-\left[{ }^{3} \mathrm{H}\right]$ Deoxy-1-glucose6-phosphate was isolated from the unphosphorylated sugar by anion-exchange chromatography, as described by Gonzalez and Garcia-Sancho ${ }^{26}$. The bars represent percent decrease in ATP levels in carotid bodies incubated for $5 \mathrm{~min}$ in the presence of 2-deoxyglucose with respect to their paired controls incubated in 2-deoxyglucose-free media; data are means of $4-8 \mathrm{ca}$ rotid bodies. Statistical comparisons: paired $t$-test. ${ }^{*} P<0.02$. 
Characteristics of the 2-DG-induced release of $\left[{ }^{3} H\right] D A$

Time-course of $\left[{ }^{3} \mathrm{H}\right] \mathrm{DA}$ release. As shown in Fig. 4 , the electrical activity elicited by 2-DG outlasts its application, probably because the phosphorylation of the accumulated 2-DG continued within the cells. Therefore, it was of interest to correlate the timecourse of 2-DG-elicited electrical activity in the CSN with the time-course of the 2-DG-induced release of $\left[{ }^{3} \mathrm{H}\right] \mathrm{DA}$. In Fig. 8 is shown the time-course of the 2-DG-induced release of [ $\left.{ }^{3} \mathrm{H}\right] \mathrm{DA}$. Note that the fraction with highest $\left[{ }^{3} \mathrm{H}\right] \mathrm{DA}$ is the post-stimulus period, despite the fact that with 2 and $4 \mathrm{mM}$ (see inset in Fig. 4), the peak of electrical activity occurred during the stimulus period. This apparent delay in $\left[{ }^{3} \mathrm{H}\right] \mathrm{DA}$ release should in fact be considered the result of washout of released $\left[{ }^{3} \mathrm{H}\right] \mathrm{DA}$. Note also in Fig. 8, that the time required for $\left[{ }^{3} \mathrm{H}\right] \mathrm{DA}$ release to return to pre-stimulus levels is about the same as that required for the electrical activity to recover to the basal level (compare Figs. 4 and 8 ). All the parallelisms between 2-DG-elicited electrical activity and $\left[{ }^{3} \mathrm{H}\right] \mathrm{DA}$ release suggest that DA plays a prominent role in the genesis of the chemoafferent activity, as already pointed out by other investigators ${ }^{10,18.19 .34 .41}$.
$\mathrm{Ca}^{2+}$ dependence of the 2-DG-evoked release of $\left[{ }^{3} H\right] D A$. The $\mathrm{Ca}^{2+}$ dependence of the 2-DG-evoked release of $\left[{ }^{3} \mathrm{H}\right] \mathrm{DA}$ was studied in 4 experiments, and the results are presented in Fig. 9. In these experiments, the first and fourth cycles were made while perfusing the preparation with normal $\mathrm{Ca}^{2+}-\mathrm{Ty}$ rode, and the second and third cycles with $0 \mathrm{Ca}^{2}+\mathrm{Ty}$ rode. Note that the release of [H]DA in the two control cycles (Fig. 9A; Nos. 1 and 4) is quite different. being much more pronounced in the last cycle. As already mentioned (see Fig. 5). this difference probably is related to the slow depletion of the store of glycogen that was built up during the period of incubation prior to the recording period. Note also that, on the average, the 2-DG-evoked release of $\left[{ }^{3} \mathrm{H} \mid \mathrm{DA}\right.$ in the two cycles with $0 \mathrm{Ca}^{2+}$ is $141 \%$ of the basal release in these same cycles. while in the two control cycles the evoked release is $320 \%$ of the basal release $(P<0.01)$. When $1 \mathrm{mM}$ EGTA is added to the 0 $\mathrm{Ca}^{2+}$ media, there is no evoked release (not shown). The average electrical activity induced by 2-DG was also reduced in the two cycles with $0 \mathrm{Ca}^{2+}$ (Fig. 9B). Thus, it represented $175 \%$ of the basal activity in 0 $\mathrm{Ca}^{2+}$ and $273 \%$ in the control cycles $(P<0.02)$. In the presence of EGTA, the electrical activity is un-

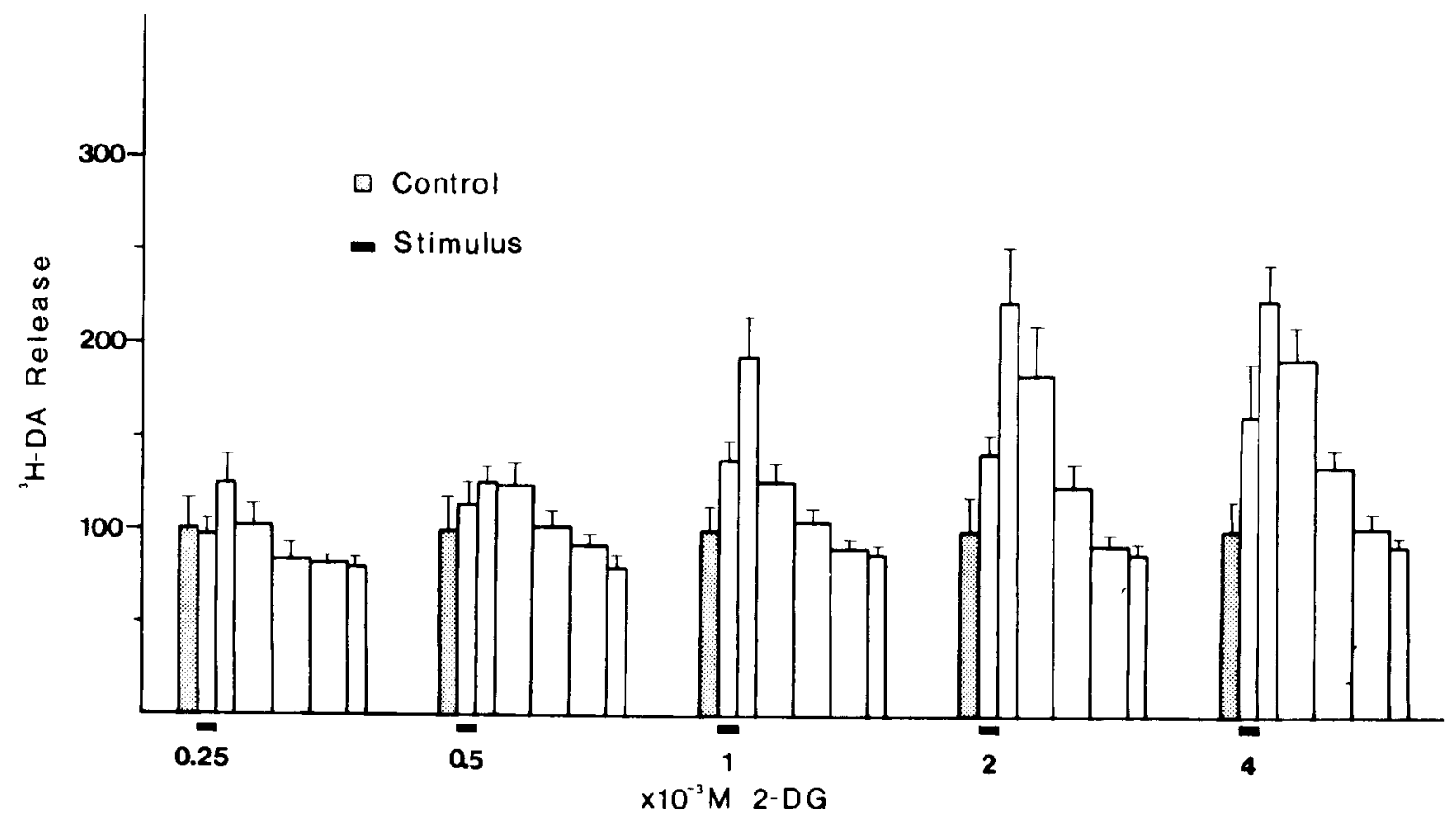

Fig. 8. Time-course of the 2-deoxy-D-glucose-evoked release of $\left[{ }^{3} \mathrm{H}\right] \mathrm{DA}$; mean values obtained in 8 stimulation cycles. In each case the basal release, release in the 5 min fraction prior to the superfusion with 2-deoxy-D-glucose, was taken as $100 \%$; in the other fractions, the release is expressed as a percentage of the basal release. 


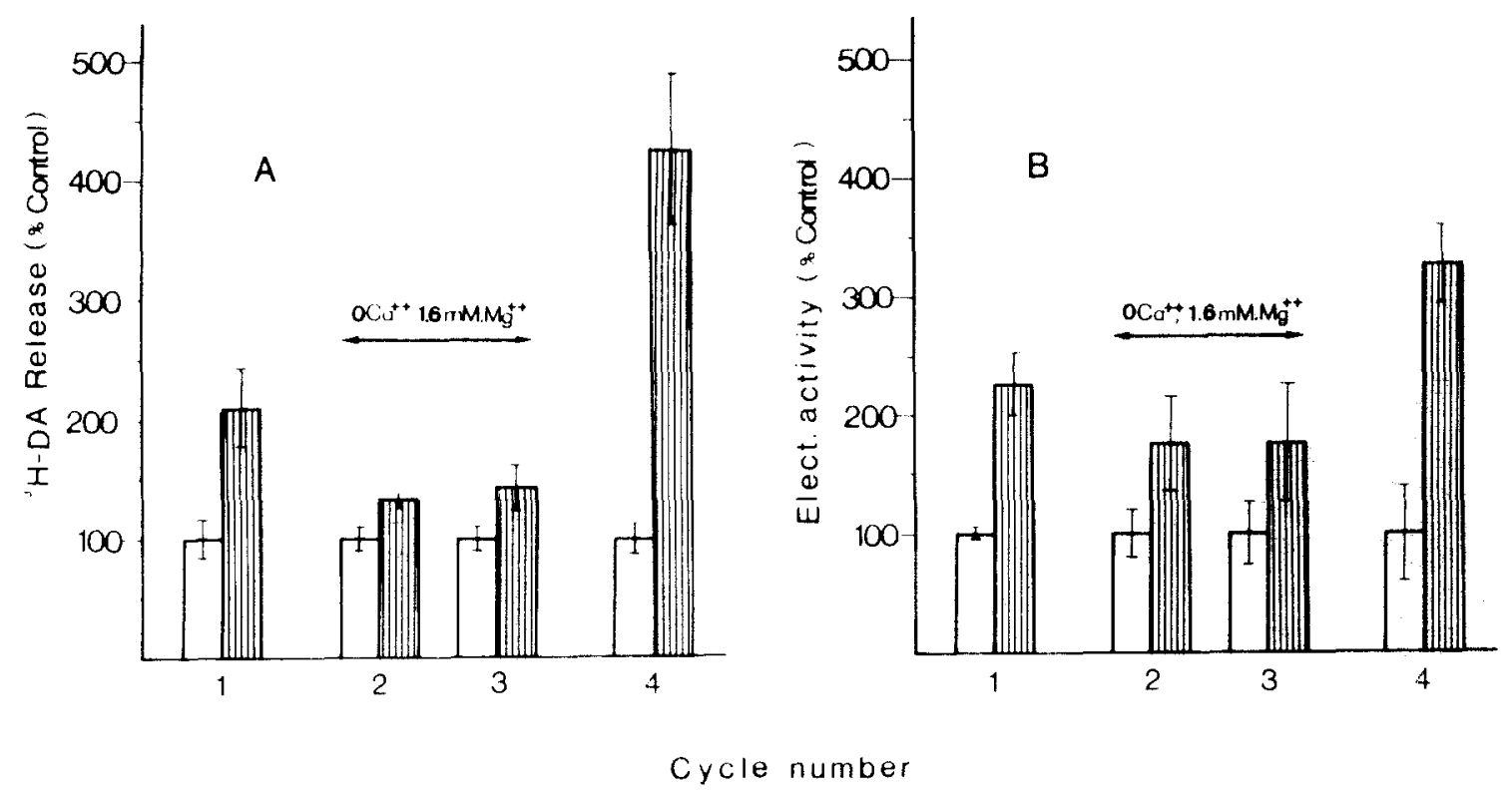

Fig. 9. Calcium dependence of the 2-deoxy-D-glucose-evoked release of [ $\left.{ }^{3} \mathrm{H}\right] \mathrm{DA}$ and electrical activity in the carotid sinus nerve. In each experiment, after the first cycle of stimulation ( $5 \mathrm{~min}$ superfusion with Tyrode-pyruvate containing $1 \mathrm{mM} 2-\mathrm{deoxy}$-D-glucose), the preparation was perfused for $30 \mathrm{~min}$ with Tyrode-pyruvate with $0 \mathrm{Ca}^{2+}+1.6 \mathrm{mM} \mathrm{Mg}^{2+}$ prior to the initiation of cycle 2 ; during cycles 2 and 3 , the superfusing medium was also $\mathrm{Ca}^{2+}$-free. Before starting cycle 4 , the preparation was superfused for 30 min with normal $\mathrm{Ca}^{2+}$-Tyrode, and cycle 4 itself was made under normal $\mathrm{Ca}^{2+}$-Tyrode. A: release of $\left[{ }^{3} \mathrm{H}\right] \mathrm{DA}$. Empty bars: basal release (100\%) in each cycle; lined bars: evoked release (as percent of the basal) in each cycle. B: electrical activity in the carotid sinus nerve. Empty bars: basal activity prior to the superfusion with 2-deoxy-D-glucose in each cycle (100\%); lined bars: peak activity evoked by 2 -deoxyglucose in each cycle as percentage of the basal activity. The data are mean values obtained in 4 experiments. The statistical comparisons described in the text were made using a paired $t$-test.

stable and almost impossible to evaluate. Again, the parallelism observed between release of $\left[{ }^{3} \mathrm{H}\right] \mathrm{DA}$ and the electrical activity in these $0 \mathrm{Ca}^{2+}$ experiments suggests a participation of DA in the genesis of the electrical activity.

\section{DISCUSSION}

The present work has investigated the metabolic hypothesis of chemoreception by correlating the effects of 2-DG on the ATP levels in the CB with the release of a putative neurotransmitter (DA) by the type I cells and with the electrical activity in the CSN. As the metabolic hypothesis postulates, there is a direct and close relationship between the decrease in ATP and the increase in DA release and CSN activity.

\section{ATP levels in the $C B$}

The mean ATP content found in our sample $(\mathrm{n}=$
70 ) of $\mathrm{CBs}$ is $3.7 \times 10^{-10} \mathrm{~mol} / \mathrm{CB}$, with a distribution which was not statistically different from that of the $\mathrm{CB}$ weights. The estimated intracellular concentration of ATP in the CB is about $2-3 \mathrm{mM}$, a concentration quite similar to that found in brain tissue 32 and liver ${ }^{53}$. Our findings contrast with the data recently reported by Acker and Starlinger ${ }^{1}$. These authors reported ATP levels of $0.087 \pm 0.056$ (S.D.) nmol/CB $(\mathrm{n}=31)$, that is, values only about $24 \%$ of ours. In the same article, it was also reported that severe hypoxia $\left(\mathrm{p}_{\mathrm{a}} \mathrm{O}_{2}=25\right.$ torr during $11 \mathrm{~min}$ ) did not modify the ATP content in the CB. Again, this observation contrasts with our previous findings ${ }^{47}$, showing that a moderate to intense hypoxic episode (incubation in air-equilibrated Tyrode for $5 \mathrm{~min}$ ) significantly reduced the ATP content in the CB. It is difficult to reconcile both sets of data since they were obtained from the same animal species; however, as pointed out in Materials and Methods (see also ref. 35), the ATP stores are very labile, and any mechanical and/or hy- 
poxic trauma to the $C B$ tissues can lead to rapid depletion of metabolically active ATP deposits. Since Acker and Starlinger ${ }^{1}$ assayed ATP in the CB directly upon removal from the animals, and considering the small size of the organ, it may be that their dissection maneuvers were responsible for the lower and greatly dispersed values which they reported. If this were the case, it is conceivable that they would not have observed a further ATP depletion following a hypoxic episode.

The decrease of the ATP levels observed in CBs incubated with pyruvate in the presence of $2-D G$ was expected considering that 2-DG is a good substrate for hexokinase and that 2-DG-6P is not a substrate for glucose phosphate isomerase $5,28.31 .51,54$. The decrease in ATP observed in the whole CB under 2-DG should result from a reduction in ATP in all glomic structures probably in direct proportion to their metabolic rate ${ }^{51}$. Because the type I cells are considered the $\mathrm{CB}$ structures with the higher metabolic rate ${ }^{56}$. they probably contribute significantly to the observed overall ATP reduction. Nonetheless, enough ATP must remain within these cells to support the exocytotic $\mathrm{Ca}^{2+}$-dependent release.

\section{2-DG as a chemostimulant}

Any agent (metabolic poison) which interferes with the generation of phosphate-bond energy is a stimulant of the $\mathrm{CB}$ chemoreceptors ${ }^{4}$. Although the metabolic poisons have many side effects, seldom considered in the context of the chemoreception process, the fact that all of them are known to decrease the ATP/ADP quotient in other structures and are powerful stimulants of the $\mathrm{CB}$ chemoreceptors has been the basis for the proposal ${ }^{4}$ of the metabolic hypothesis ${ }^{39.46 .55}$ (see refs. 7 and 17 for reviews). As was stated in the introduction, 2-DG was chosen for this study because of the apparent lack of side-effects and because it will lead to ATP depletion by increasing ATP expenditures rather than by blocking ATP synthesis, especially under our conditions of superfusion with Tyrode-pyruvate. The differences in the dose-response curves of 2-DG on the CSN activity in non-incubated or incubated CBs are, as already mentioned, in all probability due to the accumulation of glycogen during the incubation period. In addition to the observations made in the superior cervical ganglion 12.13 and adrenomedullary cells ${ }^{37}$, which show that on incubation in vitro with glucose there is an increase in glycogen deposits, we have shown ${ }^{2}$ that in CBs superfused with glucose-free Tyrode, the time required to abolish the hypoxic response is much longer if the organs are previously incubated for $3 \mathrm{~h}$ in Tyrode containing $5 \mathrm{mM}$ glucose. This delay can only be interpreted as the result of a buildup of energetic stores during the incubation period. In keeping with this notion is also the fact that the 2-DG phosphorylation curve, which has a hyperbolic shape (the correlation coefficient of $1 / \mathrm{V}$ (rate of phosphorylation) vs $1 / \mathrm{S}$ (2-DG concentration) is 10.998). has an apparent $K_{m}$ of $2.2 \mathrm{mM}$, which is much higher than that of hexokinase for 2-DG 5.22 .54 . which suggests a competitive inhibition of glucose with 2-DG even in these CBs that had not been previously incubated.

Correlation between ATP levels, release of $\left[{ }^{3} \mathrm{H} / D A\right.$ and CSN activity

The data presented in Fig. 6 and in subsequent figures show a close correlation between ATP levels, release of [ $\left.{ }^{3} \mathrm{H}\right] \mathrm{DA}$ and $\mathrm{CSN}$ activity. The metabolic hypothesis postulates such a correlation, and even more, postulates a cause-effect relationship between the decrease in the ATP levels, the release of the neurotransmitter and the genesis of activity in the CSN. A cause-effect relationship between the decrease in the ATP levels and the release of the putative neurotransmitter DA seems to exist because hy poxia and $\mathrm{CN}^{-}$, both of which decrease the ATP content in the $\mathrm{CB}$, also induce a release of DA which is $\mathrm{Ca}^{2+}$-dependent ${ }^{43}$. How a decrease in the ATP levels triggers the entry of $\mathrm{Ca}^{2+}$ into the type I cells is not known, but depolarization of the type I cells seems to be involved because organic and inorganic blockers of the voltage-dependent $\mathrm{Ca}^{2+}$ channels inhibit the hypoxic as well as the high $\mathrm{K}^{+}{ }_{0}$-induced release of $\mathrm{DA}^{44}$. These observations raise another question: how does the decrease in the ATP levels induce depolarization of the type I cells. In this regard, it is necessary to propose that an ATP-dependent electrogenic mechanism contributes to the maintenance of the membrane potential, as is also the case in other structures (see refs. 9 and 20). Consistent with this suggestion are the following observations: (1) Ouabain releases [ $\left.{ }^{3} \mathrm{H}\right] \mathrm{DA}$ from the type I cells ${ }^{2}$, an effect which is fast in onset and occurs at lower ouabain concen- 
tration than in the sympathetic endings ${ }^{41}$ (2) Ouabain depolarizes the type I cells ${ }^{t}$. (3) Cooling of the CBs also induces depolarization of the type I cells, and ouabain partially prevents the depolarization induced by lowered temperaturest. Taken together, these observations can be interpreted as due to the presence in the type I cells of an ouabain-sensitive hyperpolarizing $\mathrm{Na}^{+}-\mathrm{K}^{+}$pump, which on reduction of the ATP/ADP quotient loses its electrogenicity ${ }^{24}$, leading to depolarization. The depression of such a pump by cooling or its inhibition by ouabain will lead to depolarization".

The possible relationship between the release of putative neurotransmitters and the genesis of activity in the CSN remains to be considered. In all likelihood, all of the neuroregulators present in the type I cells (including, in addition to DA. ACh. norepinephrine (NE), Leu- and Met-enkephalins, substance P; see ref. 17) are coreleased with DA. The precise role of these neuroregulators in the chemoreception process is far from clear (see refs. 17 and 36). It is well known that exogenously applied DA can produce excitation or inhibition of the ongoing CSN activity, depending on the dose and on the animal species, but as stated by McQueen ${ }^{\text {in }}$, the real problem lies in establishing whether exogenously applied

\section{REFERENCES}

I Acker, $H$. and Starlinger, H. Adenosine triphosphate content in the cat carotid body under different arterial $\mathrm{O}_{2}$ and $\mathrm{CO}_{2}$ conditions, Neurosci. Lett., 50 (1984) 175- 179.

2 Almaraz, L., Neurotransmisores en el Proceso de Quimior. recepcion, Thesis Doctoral. Universidad de Valladolid, Spain, 1983.

3 Almaraz, L., Obeso, A. and Gonzalez, C., Metabolic dissociation of carotid body chemoreceptors responses to different types of stimulation. Preliminary findings. In D.J. Pallot (Ed.). The Peripheral Arterial Chemoreceptors, Oxford University Press, 1984, pp. 141-152

4 Anichkov, S.V. and Bellen'kii, M.L., Pharmacology of the Carotid Body Chemoreceptors, Macmillan, New York. 1963.

5 Bachelard. M.S., Clark, A.D. and Thompson, M.F., Cerebral cortex hexokinases. Elucidation of reaction mechanisms by substrate and dead-end inhibitor kinetic analysis, Biochem. J.. 123 (1971) 707-715.

6 Baron. M. and Eyzaguirre. C.. Effects of temperature on some membrane characteristics of carotid body cells, Am. J. Physiol., 233 (1977) C35-C46.

7 Belmonte, $\mathrm{C}$. and Gonzalez, C., Mechanisms of chemoreception in the carotid body: possible models. In H. Acker and R.G. O'Regan (Eds.), Phvsiologv of the Peripheral Ar-
DA has similar actions to that which is endogenously released within the tissues. On the basix of pharma cological experiments, Docherty ${ }^{10}$ and Nolan et al." have suggested that endogenous DA may in fact be excitatory. contrary to their previous suggestions 11,14 . The findings reported in this and in previous works ${ }^{1 \times, 14.43 .45}$, correlating synthesis and release of $\left[{ }^{3} \mathrm{H}\right] \mathrm{DA}$ with the activity in the CSN fit with the notion that DA plays a role in the genesis of the CSN activity, as suggested by Leitner at al :4

In conclusion. as the metabolic hypothesis postulates. our results show that there is a linkage between ATP decrease in the CB and increase in CSN activity, which appears to represent the physiological mechanism for chemoreception of hypoxia. In all likelihood, this ATP-coupled mechanism is not the only one present in the $\mathrm{CB}$. Alternative pathways currently under investigation appear to be responsible for chemoreception to low $\mathrm{pH}$ and high $\mathrm{pCO}_{2}$,

\section{ACKNOWLEDGEMENTS}

The authors thank Vicki Skelton for her skillful assistance in preparing the manuscript. This work has been supported by a grant from the CAICT of Spain .

terial Chemoreceptors, Elsevier, Amsterdam, 1983, pf $107-220$

8 Brown, A.M., ATP and ATPase determinations in red blood cells. In J.C. Ellroy and J.C. Young (Eds.), Red Cell Membranes: A Methodological Approach, Academic Press. London, 1982, pp. 223-238

9 De Weer, P., Aspects of the recovery processes in nerve. In C.C. Hunt (Ed.), Neurophysiology, University Park Press. Baltimore, 1975. pp. 231-278

10 Docherty, R.J., The effects of benztropine and pargyline on the response of cat carotid chemoreceptors to sodium cyanide, acetylcholine and dopamine. J. Phvsiol. (London), 292 (1979) 53P.

11 Docherty, R.J. and McQueen, D.S. Inhibitory action of dopamine on cat carotid chemoreceptors. J. Physiol. (London), 279 (1978) 425-436.

12 Dolivo, M., Metabolism of the mammalian sympathetic ganglia, Fed. Proc., 33 (1974) 1323-1330.

13 Dolivo, M., Foroglou-Keramfus, C., Nicolesco, P., Rochramel, F. and Rouiller, C., Correlation entre la perte de function et l'etat morphologique du tissue nerveux prive de glucose, Helv. Physiol. Acta, 21 (1964) C114-Cl16.

14 Donnelly, D.F., Smith E.J. and Dutton. R.E.. Neural re sponse of carotid chemoreceptors following dopamine blockade. J. Appl. Physiol. Respir. Environ. Exercise Physiol., 50(1981) 172-177 
15 Erhan, B., Mulligan, E. and Lahiri, S., Metabolic regulation of aortic chemoreceptor responses to $\mathrm{CO}_{2}$, Neurosci. Lett., 24 (1981) 143-147.

16 Farnebo, L.O., Release of monoamines evoked by field stimulation. Studies on some ionic and metabolic requirements, Acta Physiol. Scand., Suppl., 371 (1971) $19-27$.

17 Fidone, S. and Gonzalez, C., Initiation and control of the chemoreceptor activity in the carotid body. In J.G. Widdicombe (Ed.), Handbook of Physiology. The Respiratory System II, Am. Physiol. Soc. Washington, DC, in press.

18 Fidone, S.J., Gonzalez, C. and Yoshizaki, K., Effects of hypoxia on catecholamine synthesis in rabbit carotid body in vitro, J. Physiol. (London), 333 (1982) 81-91.

19 Fidone, S.J., Gonzalez, C. and Yoshizaki, K., Effects of low oxygen on the release of dopamine from the rabbit carotid body in vitro, J. Physiol. (London), 333 (1982) $93-110$

20 Fleming. W.W., The electrogenic $\mathrm{Na}^{+}-\mathrm{K}^{+}$pump in smooth muscle: physiological and pharmacological significance, Annu. Rev. Pharmacol. Toxicol., 20 (1980) $129-149$.

21 Fleming, R.M. and Clark, W.G., Quantitative thin-layer chromatographic stimulation of labelled dopamine and norepinephrine, their precursors and metabolites, J. Chromatogr., 52 (1970) 305-312.

22 Fonaini, G., Dacha, M., Magnani, M. and Stocchi, V.. Hexokinase from rabbit red blood cells. In W.A. Wood (Ed.), Methods in Enzymology, Vol. 90, Carbohydrate Metabolism, Academic Press. New York, 1982, pp. 3-10.

23 Gallego, R., Eyzaguirre, C. and Monti-Bloch, L., Thermal and osmotic responses of arterial receptors, $J$. Neurophysiol., 42 (1979) 665-680).

24 Glynn, I.M. and Karlish, S.J.D., The sodium pump, Annu. Rev. Physiol., 37 (1975) 13-55.

25 Gonzalez. C.. Neurotransmission en el cuerpo Carotideo, Thesis doctoral, Universidad de Valladolid. Spain. 1977.

26 Gonzalez, C. and Garcia-Sancho, H., A sensitive assay for ATP. Anal. Biochem., 114 (1981) 285-287.

27 Holmsem. H., Kaplan, K.L. and Dangelmaier, C.A., Differential energy requirements for platelet responses, Biochem. J., 208 (1982) 9-18.

28 Horton, R.W., Meldrum, B.S. and Bachelard, H.S., Enzymic and cerebral metabolic effects of 2-deoxyglucose, J. Neurochem., 21 (1973) 507-520.

29 Kirpekar, S.M., Prat, J.C. and Yamamoto, H., Effects of metabolic inhibitors on norepinephrine release from the perfused spleen of the cat. J. Pharmacol. Exp. Ther., 172 (1970) $342-350$.

30 Kondo, H., Iwanaga, T. and Nakajima, T., Immunocytochemical study on the localization of neuron specific enolase and S-100 protein in the carotid body of rats, Cell Tissue Res., 227 (1982) 291-295.

31 Kondo, T. and Beutler, E., Depletion of red cell ATP by incubation with 2-deoxyglucose, J. Lab. Clin. Med.. 94 (1979) 617-623.

32 Ksiezak, H.J. and Gibson, G., Oxygen dependence of glucose and acetylcholine metabolism in slices and synaptosomes from rat brain, $J$. Neurochem., 37 (1981) 305-314.

33 Le Dourain. H., Le Lievre, C. and Fontaine, J., Recherches experimentales sur l'origine embryologique du corps carotidien chez les oiseaux, C. R. Acad. Sci. (Paris) Ser. D, 275 (1972) 503-586.

34 Leitner, I. M. . Roumy, M. and Verna, A., In vitro record- ing of chemoreceptor activity in catecholamine-depleted rabbit carotid bodies, Neuroscience, 10 (1983) 883-891.

35 Lowry, O.H. and Passonneau, J.U., A Flexible System of Enzymatic Analysis, Academic Press, New York, 1972.

36 McQueen, D.S., Pharmacological aspects of putative transmitters in the carotid body. In H. Acker and R.G. O'Regan (Eds.), Physiology of the Peripheral Arterial Chemoreceptors, Elsevier, Amsterdam, 1983, pp. 149-195.

37 Millaruelo, A., Sagarra, M.R. and Miras-Portugal, M., Glycogen metabolism in bovine adrenal medulla. $J$. Neurochem., 38 ( 1982) 470-476.

38 Mills, E. and Jobsis, F.F., Mitochondrial respiratory chain of carotid body and chemoreceptor response to changes in oxygen tension, J. Neurophysiol., 5 (1972) 405-428

39 Mulligan, E. and Lahiri, S., Mitochondrial oxidative metabolism and chemoreception in the carotid body. In $\mathrm{C}$. Belmonte, D. Pallot, H. Acker and S. Fidone (Eds.), Arterial Chemoreceptors, Leicester University Press. Leicester, 1981, pp. 316-326.

40 Nakazato, Y., Ohga, A. and Onoda, Y., The effect of ouabain on noradrenaline output from peripheral adrenergic neurons of isolated guinea pig vas deferens, J. Physiol. (London), 278 (1978) 45-54.

41 Nolan, W.F., Donnelly, D.F., Smith, E.J, and Dutton, R.E., Inhibition of carotid body chemoreception by haloperidol in vitro, Fed. Proc. Fed. Am. Soc. Exp. Biol, 43 (1984) 813

42 Obeso. A., Almaraz, L. and Gonzalez, C. Effect of 2-deoxyglucose on carotid body chemoreceptors, Soc. Neur()sci. Abstr., 9 (1983) 682.

43 Obeso, A.. Almaraz, L. and Gonzalez. C., Correlation between ATP levels. dopamine release and electrical activity in the carotid body. Support for the metabolic hypothesis. Brain Research, in press.

44 Obeso, A., Gonzalez, C. and Fidone, S., Stimulus-secretion coupling in the carotid body chemoreceptors, Fed. Proc. Fed. Am. Soc. Exp. Biol., in press.

45 Rigual, R., Gonzalez, E., Fidone. S and Gonzalez, C., Effects of low $\mathrm{pH}$ on synthesis and release of catecholamines in the cat carotid body in vitro, Brain Research. 309 (1984) $178-181$

46 Roumy, M. and Leitner, L.M., Role of calcium ions in the mechanisms of arterial chemoreceptor excitation. In H Acker, S. Fidone, D. Pallot, C. Eyzaguirre, D.W. Lubbers and R.W. Torrance (Eds.), Chemoreception in the Carotid Body, Springer. Berlin, 1977. pp. 257-263.

47 Rubin, R.P., The role of energy metabolism in $\mathrm{Ca}^{++}$ evoked secretion from the adrenal medulla, J. Physiol. (London), 206 (1970) 181-192.

48 Rubin, R.P. Calcium and the Secretory Process. Plenum Press, New York, 1974.

49 Rubin, R.P.. Calcium and Cellular Secretion, Plenum Press, New York, 1982.

50 Rutledge, C.O. Effect of metabolic inhibitors and ouabain on amphetamine- and potassium-induced release of biogenic amines from isolated brain tissue. Biochem. Pharmacol, 27 (1978) $511-516$.

51 Sokoloff, L.. Relation between physiological function and energy metabolism in the central nervous system. $J$. Neurechem., 29 (1977) 13-26.

52 Sokolof, L.. The radioactive deoxyglucose method. In B.W. Agranoff and M.H. Aprison (Eds.), Advances in Neurochemistry, Vol. 4. Plenum Press. New York, 1982. pp. 1-82. 
53 Soling, H.D., Anion transport through the inner mitochondrial membrane. Site of regulation of gluconeogenesis. In F. Lundquist and N. Tygstrup (Eds.), Regulation of Hepatic Metabolism, Academic Press, New York, 1974, pp. 48-61

54 Sols, A. and Crane, R.K.. Substrate specificity of brain hexokinase, J. Biol. Chem., 210 (1954) 581-595.

55 Torrance, R.W.. Prolegomena. In R.W. Torrance (Ed.). Arterial Chemoreceptors, Blackwell, Oxford, 1968, pp. $1-40$.
56 Verna. A., Ultrastructure of the carotid body in mammals. Int. Rev. Cytol., $60(1979) 271-330$

57 Vizi, E.S., Stimulation by inhibition of $\left(\mathrm{Na}^{+}, \mathrm{K}^{*}, \mathrm{Mg}^{++}\right) \mathrm{at}$ tivated ATPase of acetylcholine release in cortical slices from rat brain, J. Physiol (London), 226 (1972) 95-117.

58 Weil-Malherbe, H., Determination of catecholamines. In D. Glick (Ed.). Analysis of Biogenic Amines and Their Related Enzymes, Interscience Publishers, New York, 1971. pp. $119-152$. 